\title{
Waiting time before NDT of welded offshore steel grades under consideration of delayed hydrogen-assisted cracking
}

\author{
Eugen Wilhelm ${ }^{1}$ (D) $\cdot$ Tobias Mente $^{1} \cdot$ Michael Rhode ${ }^{1,2}$
}

Received: 15 September 2020 / Accepted: 23 December 2020 / Published online: 28 January 2021

(C) The Author(s) 2021

\begin{abstract}
Offshore wind turbines (OWT) are a major goal of the energy strategy of Germany encompassing the increase of the installed wind power. OWT components are manufactured from welded steel plates with thicknesses up to $200 \mathrm{~mm}$. The underlying standards and technical recommendations for construction of OWTs encompass specifications of so-called minimum waiting time (MWT) before non-destructive testing of the weld joints is allowed. Reason is the increased risk of time-delayed hydrogenassisted cold cracking as hydrogen diffusion is very slow due to the very thick plates. The strict consideration of those long MWT up to $48 \mathrm{~h}$ during the construction of OWTs leads to significant financial burden (like disproportionately high costs for installer ships as well as storage problems (onshore)). In this study, weld joints made of S355 ML were examined in comparison with the offshore steel grade S460 G2+M. The aim was to optimize, i.e., reduce, the MWT before NDT considering varied heat input, hydrogen concentration and using self-restraint weld tests. This would significantly reduce the manufacturing time and costs of OWT construction. To quantify the necessary delay time until hydrogen-assisted cold cracks appear, acoustic emission analysis was applied directly after welding for at least $48 \mathrm{~h}$.
\end{abstract}

Keywords Welding (GMA) · Offshore steels · Non-destructive testing (NDT) · Diffusible hydrogen Tekken test

\section{Introduction}

\subsection{Welding and waiting time before NDT}

For the aim of increasing the renewable energy generation, many offshore wind turbines (OWT) will have to be installed (20 GW wind power till the year 2030) [1,2]. Foundation concepts for OWTs are mostly monopiles (76\%) or tripods [3]. Nearly all OWT components demand excessive welding fabrication of components of structural steels and especially

Recommended for publication by Commission IX - Behaviour of Metals Subjected to Welding

Eugen Wilhelm

tobias.mente@bam.de; michael.rhode@bam.de

1 Department 9-Component Safety, Bundesanstalt für Materialforschung und -prüfung (BAM), Unter den Eichen 87, 12205 Berlin, Germany

2 Institute for Materials Science and Joining Technology, Otto-von-Guericke University, Universitätsplatz 2, 39106 Magdeburg, Germany offshore steel grades with $\mathrm{Rp}_{0.2}$ of up to $500 \mathrm{MPa}[4,5]$. The underlying standards and technical recommendations for construction of OWTs encompass specifications of minimum waiting time (MWT) before non-destructive testing (NDT) of the welded joints is allowed [6, 7]. The reason is the potential risk of time-delayed hydrogen-assisted cold cracking (HACC) as hydrogen diffusion is very slow due to the plate thickness up to $200 \mathrm{~mm}$ [8]. The necessary and recommended MWT up to $24 \mathrm{~h}$ (e.g., for S460 in accordance with DIN EN 1090-2 [6]), during manufacturing leads to significant financial burdens (e.g., external companies and several more days offshore work must be paid, or onshore storage of big components is needed). The MWT affects moreover the complete manufacturing process, because no continuous process flow during MWT is possible.

In addition, the standards for construction of OWTs do not differentiate sufficiently the available offshore steel grades [5]. Advanced thermomechanical rolled offshore steel grades like the S460 G2+M [9] offer an improved weldability due to the reduced carbon equivalent combined with excellent mechanical properties [10]. These steels can be welded with reduced heat input, without preheating and have an increased resistance against HACC [10, 12, 13]. Previous studies on 
delayed cracking in structural steels showed potential for reduction of MWT [14]. Just high-strength steels with $\mathrm{Rp}_{0.2} \geq$ $690 \mathrm{MPa}$ showed an explicit time delay for crack initiation of more than $48 \mathrm{~h}$ where first cracks appeared generally 3 to $8 \mathrm{~h}$ after welding. This was explained by the slow hydrogen diffusion of the steels due to the higher alloy content [14]. Investigations on HACC for high-strength steel grades with $\mathrm{Rp}_{0.2}<450 \mathrm{MPa}$ already showed that MWT of $48 \mathrm{~h}$ is to conservative [10] as HACC occurred within $5 \mathrm{~h}$ (maximum time delay) after welding [14]. The reason for the time delay is the slow hydrogen diffusion at low temperatures. Thicker plates mean prolonged diffusion paths for hydrogen. Hydrogen diffusion and accumulation into crack critical regions (i.e., areas with high welding residual stresses or hardened heat affected zone- - HAZ) will take more time.

\subsection{Purpose of the present study}

In this study, welded joints made of two different thermomechanical rolled steel plates having different yield strength were examined and compared, aiming to obtain a scientific basis for the reduction of MWT before NDT. For that purpose, welding experiments using two different plate thicknesses (15 and $40 \mathrm{~mm}$ ), different weld head input, different preheat an interpass temperatures as well as varying hydrogen content had been carried out. For determination of the time until HACC appear after welding an acoustic emission (AE) measurement device, with a piezoelectric sensor was applied to the weld specimen for at least $48 \mathrm{~h}$. The duration of monitoring has been selected in accordance with common standards (i.e., DNVGL-OS-C401 [7]). Acoustic events had been determined by AE analysis depending on weld heat input, restraint intensity, and hydrogen content. After $48 \mathrm{~h}$ monitoring via $\mathrm{AE}$, the specimens had been subjected to NDT (visual testing, magnetic particle testing, $\mathrm{X}$-ray testing, and ultrasonic testing) before metallographic examination was done, to validate the signals recorded by AE.

\section{Materials and methods}

\subsection{Investigated materials}

The steel grades investigated are the S355 ML [25] and the S460 G2+M [9] each in two plate thicknesses (i.e., $15 \mathrm{~mm}$ and $40 \mathrm{~mm}$ ). Welding was carried out using a matching filler wire with a diameter of $1.2 \mathrm{~mm}$ (G $465 \mathrm{M} 21$ 4Si1) [15]. Furthermore, a flux cored filler wire (FCW) with a diameter of $1.2 \mathrm{~mm}$ (T $466 \mathrm{M} \mathrm{M} 211 \mathrm{H} 5$ ) was used [16] for comparison of hydrogen content of different filler materials. Table 1 shows the mechanical properties of the steel grades and welding consumables used. Table 2 shows the corresponding chemical composition according to the manufacture's certificates backed up by own measurements using atomic emission spectroscopy (AES).

To reproduce a high-restraint intensity like it occurs in a real thick plate of an OWT weld joints, a modified Tekken test geometry [17] (Tekken test sample-modTTS) (see Fig. 2) was used as a cold cracking test and compared to test samples under free shrinkage condition (free shrinkage sample-FSS) (Fig. 1a). The Tekken test is a self-restraint cold cracking test using a slotted specimen (closed slot). It is designed to access the cold cracking susceptibility of base materials (BM) and filler materials (FM) during arc welding. The restraint intensity $\left(R_{\mathrm{Fy}}\right)$ of the test can be varied by using different specimen geometries (i.e., plate thickness) and weld shapes, described in $[17,18]$.

\subsection{Welding experiments}

All welding experiments were performed using an automated gas metal arc welding (GMAW) process with V-grooved multi-pass butt joints (geometry see Fig. 1c). The weld seam opening angle was $60^{\circ}$. All welding experiments were carried out using a stick out of $18 \mathrm{~mm}$. GMAW was selected specifically enabling variation of hydrogen content in the weld joint via shielding gas. The geometry of the free shrinking samples (FSS) and modTTS are shown in Figs. 1 and 2.

Both materials, the S460 G2+M and the S355 ML were investigated in two different plate thicknesses having different restraint intensities (see Figs. 1b, c and 2) and varying amounts of initial hydrogen concentrations labeled with low HD and high HD. The restraint intensity for the modTTS was calculated by FEM, according to [13], with $3 \mathrm{kN} /(\mathrm{mm} \times \mathrm{mm})$ and $7 \mathrm{kN} /(\mathrm{mm} \times \mathrm{mm})$ for $15 \mathrm{~mm}$ - and $40 \mathrm{~mm}$-thick plates, respectively.

- Low HD represents a welding process using a standard shielding gas under strict consideration of the rules and standards for a clean processing of the materials.

- High HD represents a maximum hydrogen content (anticipated with high risk for HACC), i.e., wet filler materials, high humidity, or insufficient gas shielding and was achieved using a shielding gas with addition of hydrogen.

For low $\mathrm{HD}$, the shielding gas $\mathrm{M} 21\left(18 \% \mathrm{CO}_{2}\right.$ and $82 \%$ Ar, in accordance with DIN EN ISO 14175: M21-ArC-18) and for high $\mathrm{HD}$, the shielding gas $\mathrm{R} 1(5 \% \mathrm{H} 2$ in $95 \% \mathrm{Ar}$, in accordance with DIN EN ISO 14175: R1-ArH-5) [19] was used.

The corresponding hydrogen concentration that was introduced to the weld joint by using different filler materials and shielding gases was determined in accordance with ISO 3690 [11]. Three ISO samples per parameter set were investigated, see Table 3. 
Table 1 Mechanical properties of base materials and welding consumables investigated (according to manufacturer specification)

\begin{tabular}{|c|c|c|c|c|c|}
\hline \multicolumn{2}{|c|}{ Material (and thickness) } & \multirow{2}{*}{$\begin{array}{l}\text { Yield strength } \\
{\left[\mathrm{Rp}_{0.2}\right] \text { in } \mathrm{MPa}}\end{array}$} & \multirow{2}{*}{$\begin{array}{l}\text { Tensile strength } \\
{\left[\mathrm{R}_{\mathrm{m}}\right] \text { in } \mathrm{MPa}}\end{array}$} & \multirow{2}{*}{$\begin{array}{l}\text { Elongation } \\
{\left[A_{5}\right] \text { in } \%} \\
26\end{array}$} & \multirow{2}{*}{$\begin{array}{l}\text { Impact toughness } \\
{\left[\mathrm{A}_{\mathrm{V}}\right] \text { in } \mathrm{J}} \\
108\left(-40^{\circ} \mathrm{C}\right)\end{array}$} \\
\hline $\mathrm{BM}$ & $\mathrm{S} 460 \mathrm{G} 2+\mathrm{M}, h=15 \mathrm{~mm}$ & & & & \\
\hline & $\mathrm{S} 460 \mathrm{G} 2+\mathrm{M}, h=40 \mathrm{~mm}$ & 453 & 563 & 27.5 & $204\left(-40^{\circ} \mathrm{C}\right)$ \\
\hline & $\mathrm{S} 355 \mathrm{ML}, h=15 \mathrm{~mm}$ & 447 & 539 & 33 & $157\left(-50^{\circ} \mathrm{C}\right)$ \\
\hline & BM: S355 ML, $h=40 \mathrm{~mm}$ & 495 & 577 & 24 & $323\left(-50^{\circ} \mathrm{C}\right)$ \\
\hline \multirow[t]{2}{*}{ FM } & G 465 M 21 4Si1 & 460 & 530 & 20 & - \\
\hline & T $466 \mathrm{M} \mathrm{M} 1 \mathrm{H} 5$ & 460 & $>550$ & 26 & - \\
\hline
\end{tabular}

$B M$ base material, $F M$ filler metal

A test matrix was developed that included the variation of weld heat input, hydrogen content, specific restraint intensity of the samples (free shrinking sample: FSS vs. modTTS) and preheat/interpass temperature $\left[T_{\mathrm{p} / \mathrm{i}}\right]$. The test matrix is shown in Fig. 3, the points 1, 4, 5, and 8 represent the FSS welding experiments and the green points $2,3,6$, and 7 the modTTS welding experiments using 40 -mm-thick steel plates. Test points "RP1" and "RP2" are modTTS having 15-mm plate thickness. The bottom level of the matrix represents the experiments with the shielding gas M21 (low HD). The welding experiments in the top level of the matrix were examined using the shielding gas R1 with addition of 5\% hydrogen (high HD).

The preheat $\left[T_{\mathrm{p}}\right]$ and interpass temperature $\left[T_{\mathrm{i}}\right]$ for the points $1,2,5$, and 6 was $50^{\circ} \mathrm{C}$. The temperature for the points $3,4,7$, and 8 was $150^{\circ} \mathrm{C}$. The welding voltage (arc voltage) for the low-HD and high-HD experiments was virtually identical (see Table 4). No remarkable difference of the arc voltage could be observed between the shielding gas mixtures. For a better overview, all parameters of the different welding experiments are summarized in Table 4. The experiments for the S460 are summarized in the bottom part of Table 4 (M-Point: A to D). These are additional welding experiments that were compared to the welding experiments using the S355 ML via the reference points "RP1" and "RP2". The preheat and interpass temperature of the additional experiments as well as reference points was $100{ }^{\circ} \mathrm{C}$.

In accordance with EN ISO 3690 [11], twelve samples were investigated, see Table 3. The ISO samples consist of three parts with a thickness of $15 \mathrm{~mm}$ : a run-on, center, and run-off piece, whereas only the center piece is used for hydrogen determination (samples were annealed before hydrogen determination to ensure that specimens are free from hydrogen before testing). The base material for the samples was the S355 ML. To determine the diffusible hydrogen concentration of the filler materials used at normal conditions (without extra HD), welding experiments with M21 shielding gas were performed. For reproducing a non-perfect welding experiment resulting in higher hydrogen concentrations, both filler materials were welded using the shielding gas with addition of 5\% hydrogen ("R1") to quantify the diffusible hydrogen concentration adsorbed during welding. Additional details regarding the ISO 3690 welding procedure and test sequence can be found in Ref. [11, 20, 21].

In addition to the ISO 3690 samples, multi-pass butt joints (free shrinking sample geometry with $15 \mathrm{~mm}$ ) were used, welded, and analyzed to investigate the influence of multiple welding thermal cycles, i.e., real welds on hydrogen content in

Table 2 Chemical composition in wt.-\% of base material (BM) and filler materials (FM): Fe-balance, in accordance with manufacturer specification and own measurements $(\mathrm{OM})$ by AES

\begin{tabular}{|c|c|c|c|c|c|c|c|c|c|c|c|c|c|}
\hline & Steel grade/thickness & $\mathbf{C}$ & $\mathbf{S i}$ & Mn & $\mathbf{P}+\mathbf{S}$ & $\mathbf{C r}$ & Mo & $\mathbf{N i}$ & $\mathrm{Cu}$ & $\mathbf{N}$ & Al & $\mathbf{N b}$ & $\mathbf{T i}+\mathbf{V}$ \\
\hline \multirow[t]{6}{*}{$\mathrm{BM}$} & $\mathrm{S} 355 \mathrm{ML}, h=15 \mathrm{~mm}$ & 0.14 & 0.49 & 1.55 & 0.02 & 0.03 & 0.01 & 0.04 & 0.02 & - & 0.03 & 0.02 & 0.003 \\
\hline & OM-AES & 0.15 & 0.49 & 1.48 & 0.01 & 0.04 & 0.01 & 0.02 & 0.02 & - & 0.04 & 0.01 & 0.004 \\
\hline & $\mathrm{S} 355 \mathrm{ML}, h=40 \mathrm{~mm}$ & 0.07 & 0.37 & 1.62 & 0.02 & 0.04 & 0.01 & 0.03 & 0.02 & 0.005 & 0.03 & 0.02 & 0.003 \\
\hline & OM-AES & 0.03 & 0.37 & 1.59 & 0.02 & 0.04 & 0.01 & 0.03 & 0.02 & - & 0.04 & 0.03 & 0.006 \\
\hline & $\mathrm{S} 460 \mathrm{G} 2+\mathrm{M}, h=15 \mathrm{~mm}$ & 0.11 & 0.50 & 1.59 & 0.02 & 0.03 & 0.01 & 0.02 & 0.07 & 0.004 & 0.03 & 0.03 & 0.002 \\
\hline & OM-AES & 0.10 & 0.51 & 1.53 & 0.01 & 0.04 & 0.01 & 0.03 & 0.08 & - & 0.04 & 0.03 & 0.004 \\
\hline \multirow[t]{4}{*}{$\mathrm{FM}$} & G 465 M 21 4Si1 & 0.07 & 0.88 & 1.64 & 0.02 & 0.03 & 0.00 & 0.02 & 0.04 & 0.003 & 0.00 & 0.00 & 0.012 \\
\hline & OM-AES & 0.07 & 0.89 & 1.64 & 0.02 & 0.03 & 0.01 & 0.02 & 0.04 & - & 0.03 & 0.00 & 0.013 \\
\hline & T 466 M M 1 H5 & 0.07 & 0.77 & 1.54 & 0.02 & 0.01 & 0.00 & 0.01 & 0.12 & 0.001 & 0.00 & 0.00 & 0.016 \\
\hline & OM-AES & 0.07 & 0.80 & 1.54 & 0.02 & 0.01 & 0.01 & 0.01 & 0.16 & - & 0.01 & 0.00 & 0.013 \\
\hline
\end{tabular}



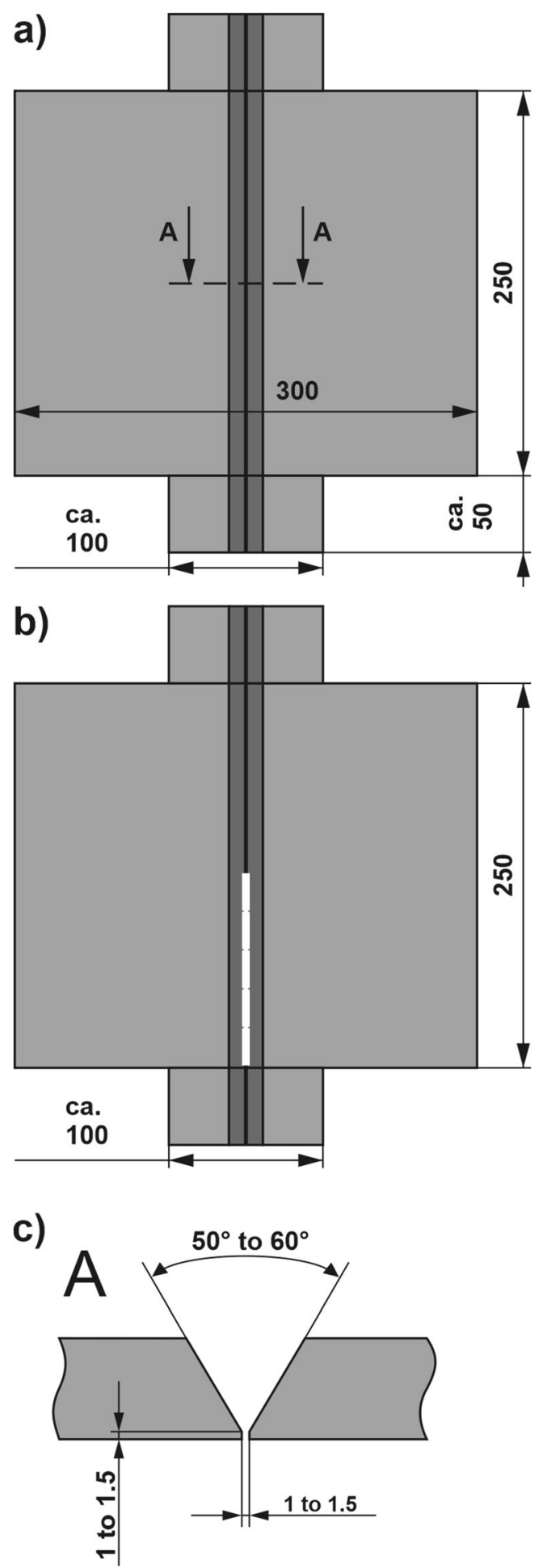

Fig. 1 Geometry of a free shrinking sample (FSS), b free shrinking sample with extracted specimen for hydrogen analysis, and $\mathbf{c} \mathrm{V}$-groove dimension for all samples

weld joint (see Fig. 1b). The geometry of the specimens was adopted to modTTS specimens in order to gain information on the hydrogen concentration in the multi-pass welds and multiple heated modTTS samples compared to the ISO specimens. Additionally, the relatively short weld length should guarantee a nearly constant hydrogen concentration over the whole length of the weld. This was proven by extracting samples at different positions in the weld. After welding, the weld joint was immediately placed in ice water to remove the residual heat before storing in liquid nitrogen ($196^{\circ} \mathrm{C}$ ) preventing hydrogen effusion. For analyzing the hydrogen concentration (HD - diffusible hydrogen concentration) in the weld, specimens were extracted from the weld metal by water jet cutting (see Fig. 4).

Accordingly, higher hydrogen concentration appears more over the thickness of the sample than over the length of the weld seam and to keep the cutting process as short as possible the extraction was started from the weld start. Nevertheless, the starting point for extracting samples out of the weld was varied. Extracted samples starting from middle of the weld to the end of the weld showed mostly the same hydrogen concentration as samples that were extracted from the weld start. Cutting process for each extracted block with five specimens took 15 to $20 \mathrm{~min}$. and the extracted specimens were labeled

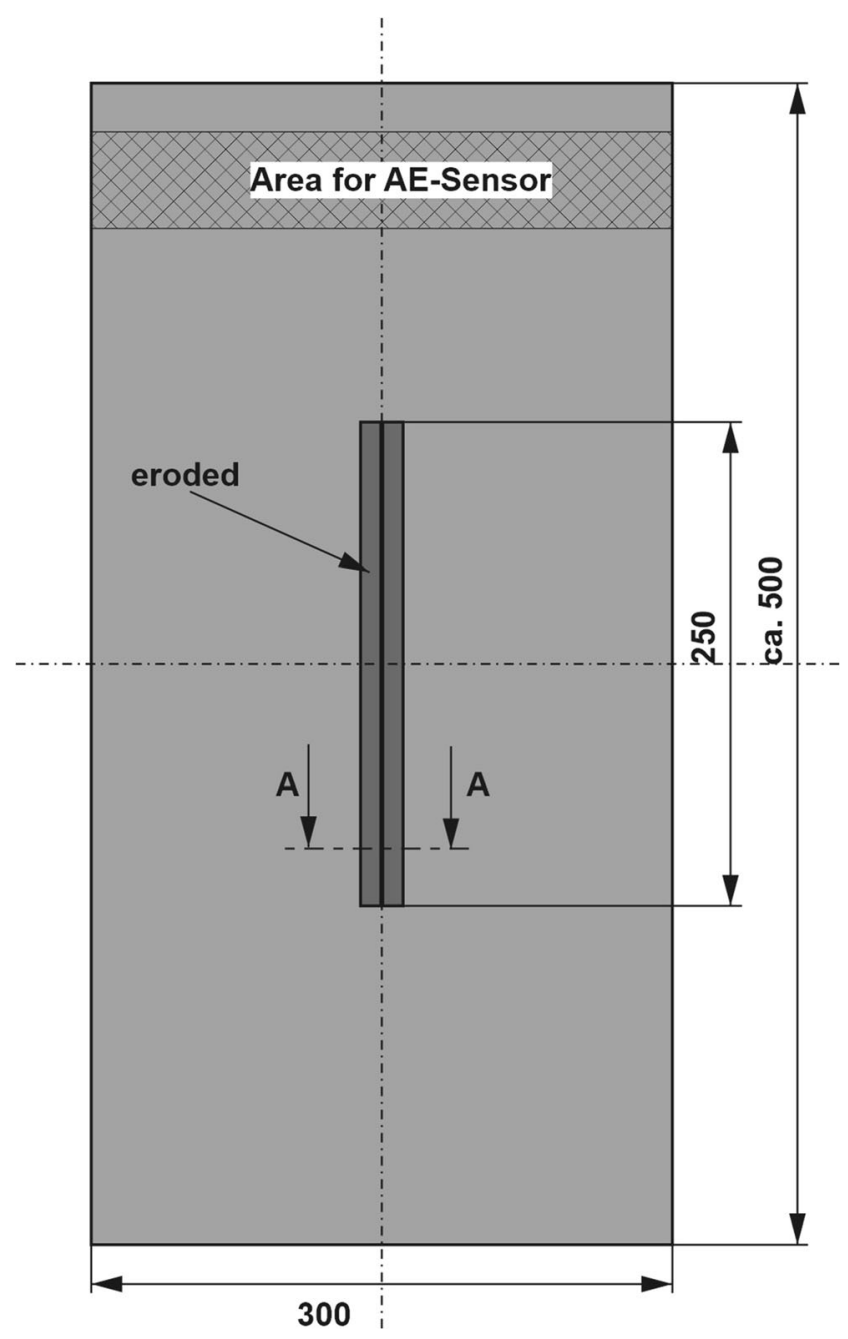

Fig. 2 Dimension of the modTTS sample 
Table 3 EN ISO 3690 [11] welding experiments for basic diffusible hydrogen determination using different filler materials and shielding gases used

\begin{tabular}{llll}
\hline Number of exp. & Filler material & Shielding gas & $E[\mathrm{~kJ} / \mathrm{mm}]$ \\
\hline $3 \mathrm{x}$ & Solid wire & M21 & 1.2 \\
$3 \mathrm{x}$ & Solid wire & R1 & 1.2 \\
$3 \mathrm{x}$ & Flux cored wire & M21 & 1.2 \\
$3 \mathrm{x}$ & Flux cored wire & R1 & 1.2 \\
\hline
\end{tabular}

with ML1 to ML5 (see Fig. 4). The specimens for hydrogen analysis in S460 multi-pass weld were labeled with G1 to G5, respectively. The size of the specimens was $20 \mathrm{~mm} \times 3 \mathrm{~mm}$ (length $\times$ width), height correspond to the specific plate thickness. After determination of the diffusible hydrogen concentration in the specimens was done (see Section 2.3), multilayer weld tests with $15-\mathrm{mm}$ and 40 -mm-thick plates (FSS and modTTS) according to Table 4 were performed. All welding process parameters (e.g., welding current or wire feed speed) for all experiments (see Table 4) were monitored and the heat input $E$ in $\mathrm{kJ} / \mathrm{mm}$ was calculated. The $t_{8 / 5}$-cooling time was determined by dipping thermocouples into the liquid weld metal.

\subsection{Hydrogen analysis}

The corresponding hydrogen concentration in the specimens was measured in accordance with ISO 3690 [11] using a calibrated JUWE H-MAT 221 (Bruker G4). The instrument uses carrier gas hot extraction (CGHE) method with a coupled thermal conductivity detector (TCD). Before analysis was

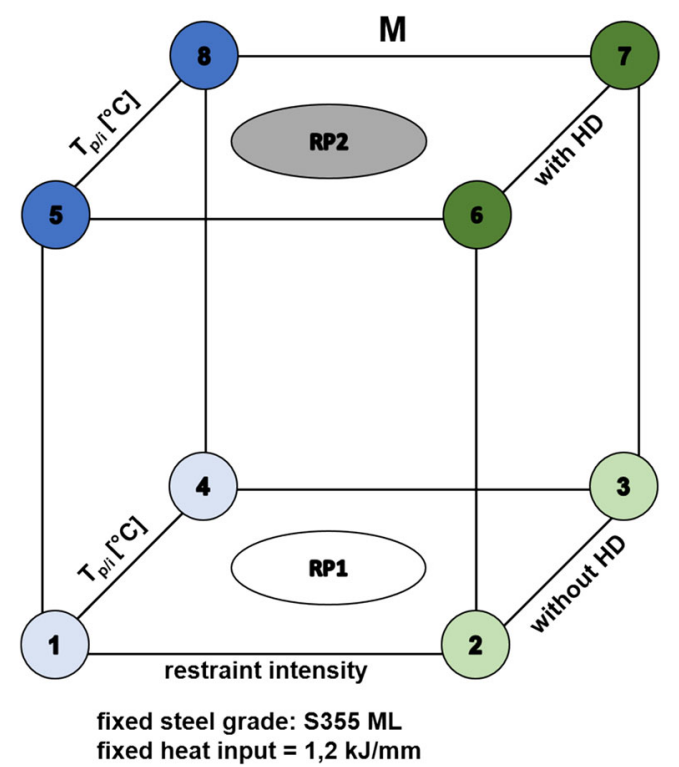

Fig. 3 Test Matrix including all welding experiments for S355 ML in $15 \mathrm{~mm}$ and $40 \mathrm{~mm}$ plate thickness started, specimens were removed from the liquid nitrogen and de-iced for 60 to $120 \mathrm{~s}$ in acetone to reach ambient temperature.

For detailed description of the measurement procedure, see [20-22]. The total hydrogen concentration for both BM and FM was determined in as received condition using a BRUKER G8 Galileo system (described in [27]) as the Phoenix G4 analyzer only allows solid-state hydrogen extraction. For that purpose, small samples of the materials were melted at a temperature of $1600{ }^{\circ} \mathrm{C}$ in an impulse furnace and hydrogen was detected by mass spectrometer. Before analyzing the samples, they were cleaned with acetone and dried in a gaseous nitrogen steam.

\subsection{Acoustic emission analysis $(A E)$ for FSS and modTTS}

For determination of the time until crack initiation occurs an acoustic emission (AE) measurement device was applied, details can be found in [24]. The AE sensor (piezoelectric sensor) was placed near the weld seam (see Fig. 2 for modTTS). The AE sensor was placed at the samples when the temperature after welding was below $150^{\circ} \mathrm{C}$ to avoid damage to the sensor by thermal loads. The total measuring time was at least $48 \mathrm{~h}$ for each sample after finishing of welding (based on recommendations in $[6,7])$. AE signals were detected by their energy level and passed a filter (adjusted in software) to reduce signals to events associated with cracks. These are characterized by a specific shape of the detected signal with special spectrums and certain amounts of energy; they were detected and saved automatically. More details about AE analysis and crack detection can be found in $[23,24]$.

\section{Results and discussion}

\subsection{Hydrogen concentration in materials as received and weldsusing different shielding gases}

The total amount of hydrogen in the base material (BM) and filler material (FM) was determined by melt extraction technique. The total hydrogen concentration for base material and filler material was determined with 0.5 to $0.6 \mathrm{ml} / 100 \mathrm{~g} \mathrm{Fe}$ (BM) and 0.2 to $0.6 \mathrm{ml} / 100 \mathrm{~g} \mathrm{Fe}(\mathrm{FM})$, respectively. Thus, no critical hydrogen concentrations for the BM in as received condition (including trapped hydrogen via melt extraction).

The results of the ISO 3690 experiments are summarized in Fig. 5 (showing the mean values with corresponding deviations). The test welds performed with M21 gas show a diffusible hydrogen concentration of 1.8 to $3 \mathrm{ml} / 100 \mathrm{~g}$ Fe for both filler materials (and match the HD3 classification $[15,16]$ ), i.e., reduced HD class to avoid HACC. The measured diffusible hydrogen concentration using the shielding gas R1 with 
Table 4 Process parameters and experimental boundary conditions for all welding experiments

\begin{tabular}{|c|c|c|c|c|c|c|c|c|c|}
\hline $\begin{array}{l}\mathrm{M} \\
\text { point }\end{array}$ & $\begin{array}{l}\text { Welding } \\
\text { current }[\mathrm{A}]\end{array}$ & $\begin{array}{l}\text { Welding } \\
\text { voltage }[\mathrm{V}]\end{array}$ & $\begin{array}{l}\text { Weld. speed } \\
{[\mathrm{mm} / \mathrm{min}]}\end{array}$ & $\begin{array}{l}\text { Wire feed speed } \\
{[\mathrm{m} / \mathrm{min}]}\end{array}$ & $\begin{array}{l}\text { Preheat/interpass } \\
\text { temp. }\left[T_{\mathrm{P} / \mathrm{i}}\right]\end{array}$ & $\begin{array}{l}E[\mathrm{~kJ} / \\
\mathrm{mm}]\end{array}$ & $\begin{array}{l}\text { Realization of restraint } \\
\text { intensity }\end{array}$ & $\begin{array}{l}\text { HD } \\
\text { level }\end{array}$ & Material \\
\hline RP1 & 233 & 29.0 & 380 & 10.5 & $100^{\circ} \mathrm{C}$ & 1.2 & $\begin{array}{l}15 \mathrm{~mm} \text { TTS: } 3 \\
\mathrm{kN} /(\mathrm{mm} \times \mathrm{mm})\end{array}$ & $\begin{array}{l}\text { Low } \\
\text { HD }\end{array}$ & $\begin{array}{l}\text { S355 } \\
\text { ML }\end{array}$ \\
\hline RP2 & 245 & 31.0 & 380 & 10.5 & $100^{\circ} \mathrm{C}$ & 1.2 & $\begin{array}{l}15 \mathrm{~mm} \text { TTS: } 3 \\
\mathrm{kN} /(\mathrm{mm} \times \mathrm{mm})\end{array}$ & $\begin{array}{l}\text { High } \\
\text { HD }\end{array}$ & $\begin{array}{l}\text { S355 } \\
\text { ML }\end{array}$ \\
\hline 1 & 262 & 30.0 & 380 & 10.5 & $50^{\circ} \mathrm{C}$ & 1.2 & $\begin{array}{l}15 \mathrm{~mm} \text { FSS: } 0 \\
\mathrm{kN} /(\mathrm{mm} \times \mathrm{mm})\end{array}$ & $\begin{array}{l}\text { Low } \\
\text { HD }\end{array}$ & $\begin{array}{l}\text { S355 } \\
\text { ML }\end{array}$ \\
\hline 2 & 255 & 30.0 & 380 & 10.5 & $50^{\circ} \mathrm{C}$ & 1.2 & $\begin{array}{l}40 \mathrm{~mm} \text { TTS: } 7 \\
\mathrm{kN} /(\mathrm{mm} \times \mathrm{mm})\end{array}$ & $\begin{array}{l}\text { Low } \\
\text { HD }\end{array}$ & $\begin{array}{l}\mathrm{S} 355 \\
\mathrm{ML}\end{array}$ \\
\hline 3 & 253 & 29.5 & 380 & 10.5 & $150^{\circ} \mathrm{C}$ & 1.2 & $\begin{array}{l}40 \mathrm{~mm} \text { TTS: } 7 \\
\mathrm{kN} /(\mathrm{mm} \times \mathrm{mm})\end{array}$ & $\begin{array}{l}\text { Low } \\
\text { HD }\end{array}$ & $\begin{array}{l}\text { S355 } \\
\text { ML }\end{array}$ \\
\hline 4 & 262 & 30.0 & 380 & 10.5 & $150^{\circ} \mathrm{C}$ & 1.2 & $\begin{array}{l}15 \mathrm{~mm} \text { FSS: } 0 \\
\mathrm{kN} /(\mathrm{mm} \times \mathrm{mm})\end{array}$ & $\begin{array}{l}\text { Low } \\
\text { HD }\end{array}$ & $\begin{array}{l}\text { S355 } \\
\text { ML }\end{array}$ \\
\hline 5 & 265 & 31.0 & 380 & 10.5 & $50^{\circ} \mathrm{C}$ & 1.2 & $\begin{array}{l}15 \mathrm{~mm} \text { FSS: } 0 \\
\mathrm{kN} /(\mathrm{mm} \times \mathrm{mm})\end{array}$ & $\begin{array}{l}\text { High } \\
\text { HD }\end{array}$ & $\begin{array}{l}\text { S355 } \\
\text { ML }\end{array}$ \\
\hline 6 & 240 & 31.5 & 380 & 10.5 & $50^{\circ} \mathrm{C}$ & 1.2 & $\begin{array}{l}40 \mathrm{~mm} \text { TTS: } 7 \\
\mathrm{kN} /(\mathrm{mm} \times \mathrm{mm})\end{array}$ & $\begin{array}{l}\text { High } \\
\text { HD }\end{array}$ & $\begin{array}{l}\text { S355 } \\
\text { ML }\end{array}$ \\
\hline 7 & 235 & 32.0 & 380 & 10.5 & $150^{\circ} \mathrm{C}$ & 1.2 & $\begin{array}{l}40 \mathrm{~mm} \text { TTS: } 7 \\
\mathrm{kN} /(\mathrm{mm} \times \mathrm{mm})\end{array}$ & $\begin{array}{l}\text { High } \\
\text { HD }\end{array}$ & $\begin{array}{l}\text { S355 } \\
\text { ML }\end{array}$ \\
\hline 8 & 245 & 32.0 & 400 & 10.5 & $150^{\circ} \mathrm{C}$ & 1.2 & $\begin{array}{l}15 \text { mm FSS: } 0 \\
\mathrm{kN} /(\mathrm{mm} \times \mathrm{mm})\end{array}$ & $\begin{array}{l}\text { High } \\
\text { HD }\end{array}$ & $\begin{array}{l}\mathrm{S} 355 \\
\mathrm{ML}\end{array}$ \\
\hline $\mathrm{A}$ & 181 & 26.5 & 350 & 8.5 & $100^{\circ} \mathrm{C}$ & 0.8 & $\begin{array}{l}15 \mathrm{~mm} \text { TTS: } 3 \\
\mathrm{kN} /(\mathrm{mm} \times \mathrm{mm})\end{array}$ & $\begin{array}{l}\text { Low } \\
\text { HD }\end{array}$ & S460 \\
\hline $\mathrm{B}$ & 280 & 30.0 & 350 & 11.0 & $100^{\circ} \mathrm{C}$ & 1.6 & $\begin{array}{l}15 \mathrm{~mm} \text { TTS: } 3 \\
\mathrm{kN} /(\mathrm{mm} \times \mathrm{mm})\end{array}$ & $\begin{array}{l}\text { High } \\
\text { HD }\end{array}$ & S460 \\
\hline $\mathrm{C}$ & 182 & 26.5 & 350 & 8.5 & $100^{\circ} \mathrm{C}$ & 0.8 & $\begin{array}{l}15 \mathrm{~mm} \text { TTS: } 3 \\
\mathrm{kN} /(\mathrm{mm} \times \mathrm{mm})\end{array}$ & $\begin{array}{l}\text { Low } \\
\text { HD }\end{array}$ & S460 \\
\hline $\mathrm{D}$ & 280 & 30.0 & 350 & 10.5 & $100^{\circ} \mathrm{C}$ & 1.6 & $\begin{array}{l}15 \mathrm{~mm} \text { TTS: } 3 \\
\mathrm{kN} /(\mathrm{mm} \times \mathrm{mm})\end{array}$ & $\begin{array}{l}\text { High } \\
\text { HD }\end{array}$ & S460 \\
\hline
\end{tabular}

addition of $5 \%$ hydrogen is approximately $12 \mathrm{ml} / 100 \mathrm{~g} \mathrm{Fe}$ for both filler materials. The effect of the filler material on the diffusible hydrogen concentration is more pronounced using the shielding gas M21. The flux cored wire is more sensitive towards moisture absorption than a solid wire [26] resulting in higher absorbed hydrogen concentrations in the welds. By using the shielding gas $\mathrm{R} 1$ with addition of $5 \%$ hydrogen the

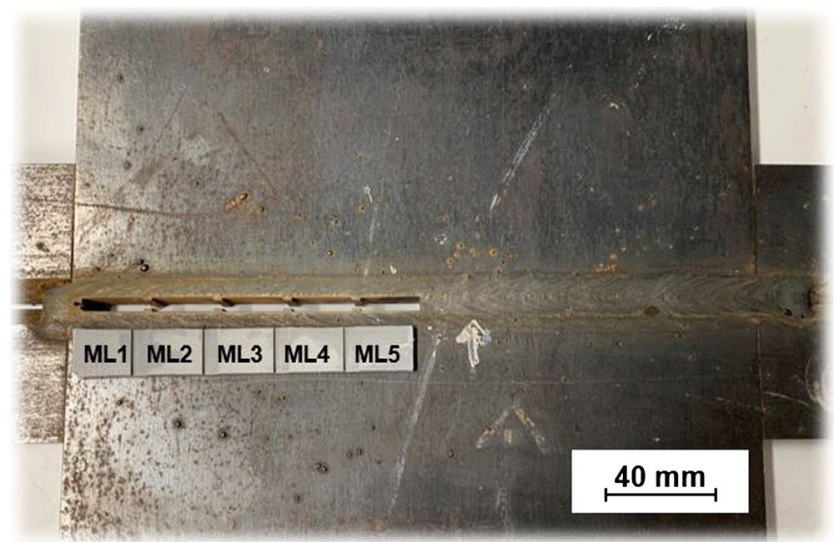

Fig. 4 Multi-pass butt joint (S355 ML) extracted sample consisting of five specimens for hydrogen analysis diffusible hydrogen concentration for both FM is in the same range. Thus, using the shielding gas $\mathrm{R} 1$ represents a worstcase scenario with high hydrogen concentration (i.e., welding with wet filler materials or contaminations at the weld seam) and was used to achieve a high risk for HACC in the welding experiments performed here [28].

\subsection{Hydrogen concentration in multi-pass welds}

Based on the ISO 3690 experiments, additional multi-pass welds were examined using the different shielding gases to gain information on the influence of multiple thermal cycles on hydrogen concentration in multi-pass welds compared to the standard ISO 3690 samples. Additionally, the weld length and welding parameters were the same as for the later welded modTTS samples. Only the solid wire was considered for these experiments as the previous results (see Fig. 5) showed that the influence of the flux cored filler wire on HD is low, especially when using the shielding gas R1 with addition of $5 \%$ hydrogen. The extracted sample from the multi-pass weld of the S355 ML (see Fig. 4) contained five small specimens that were analyzed with the G4. The process parameters 
Fig. 5 Diffusible Hydrogen concentration for ISO 3690 samples and different shielding gases (average value of three samples)

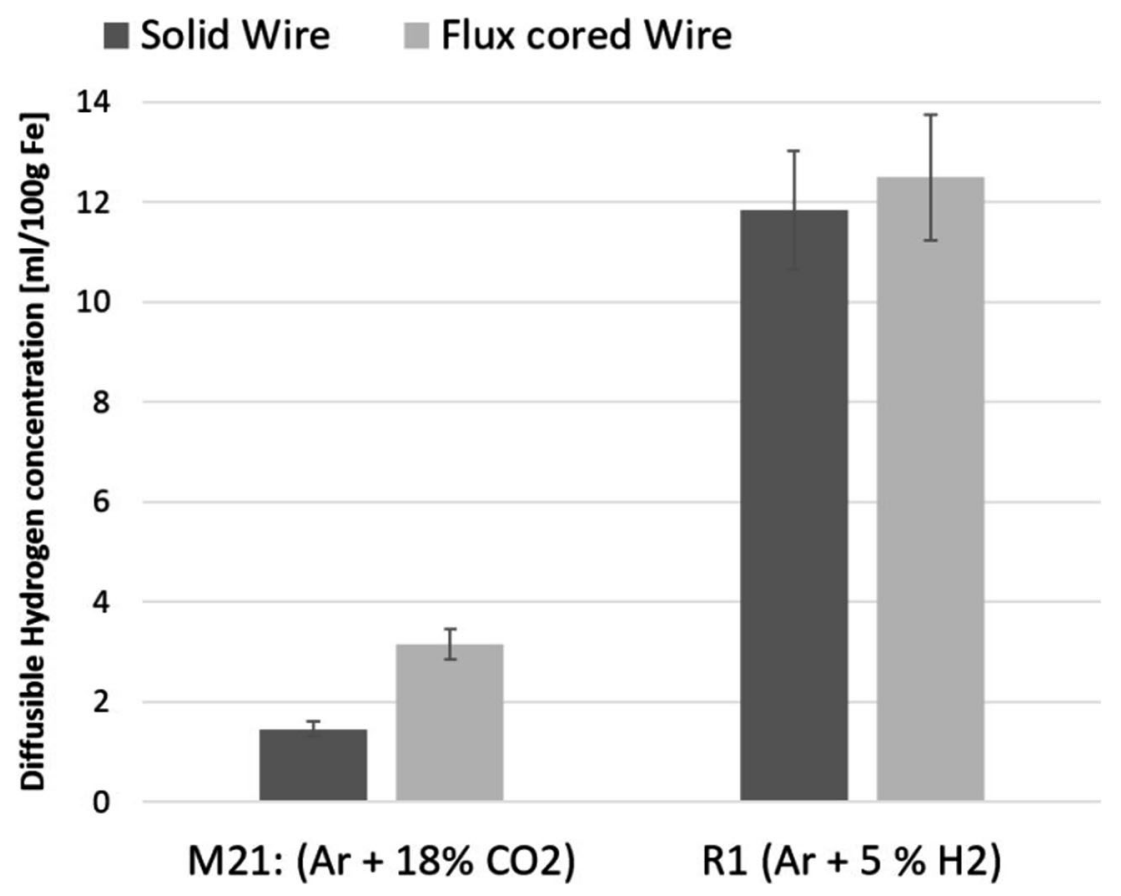

correspond to the matrix points 4 and 8 (see Table 4). The S460 was welded and analyzed with the same process parameters. The results are shown in Fig. 6 for the S355 ML and in Fig. 7 for the S460 G2+M. For that purpose, each data column represents one measured value for each position ML1 to ML5 (see Fig. 4). Based on Figs. 6 and 7, it can be derived that the diffusible hydrogen concentration obviously did not show any significant dependence on the position of extraction within the weld length ML1 to ML5.

Nonetheless, using the shielding gas M21 resulted in a hydrogen concentration below $0.5 \mathrm{ml} / 100 \mathrm{~g} \mathrm{Fe}$, i.e., very low. For that reason, the hydrogen concentration of the multi-pass weld is in between the two values measured for the base material and the solid filler wire in as delivered condition.

The influence of the shielding gas on diffusible hydrogen concentration is clearly visible for multi-pass welding. For the S355 ML, the diffusible concentration is between 3 and 3.5 $\mathrm{ml} / 100 \mathrm{~g} \mathrm{Fe}$ and for the S460 the HD is 3.4 to $3.7 \mathrm{ml} / 100 \mathrm{~g} \mathrm{Fe}$, thus nearly the same hydrogen concentration for both base materials. The slightly higher hydrogen concentration in case of the S460 G2+M perhaps results from the slightly higher
Fig. 6 Diffusible hydrogen concentration in the S355ML multi-pass weld

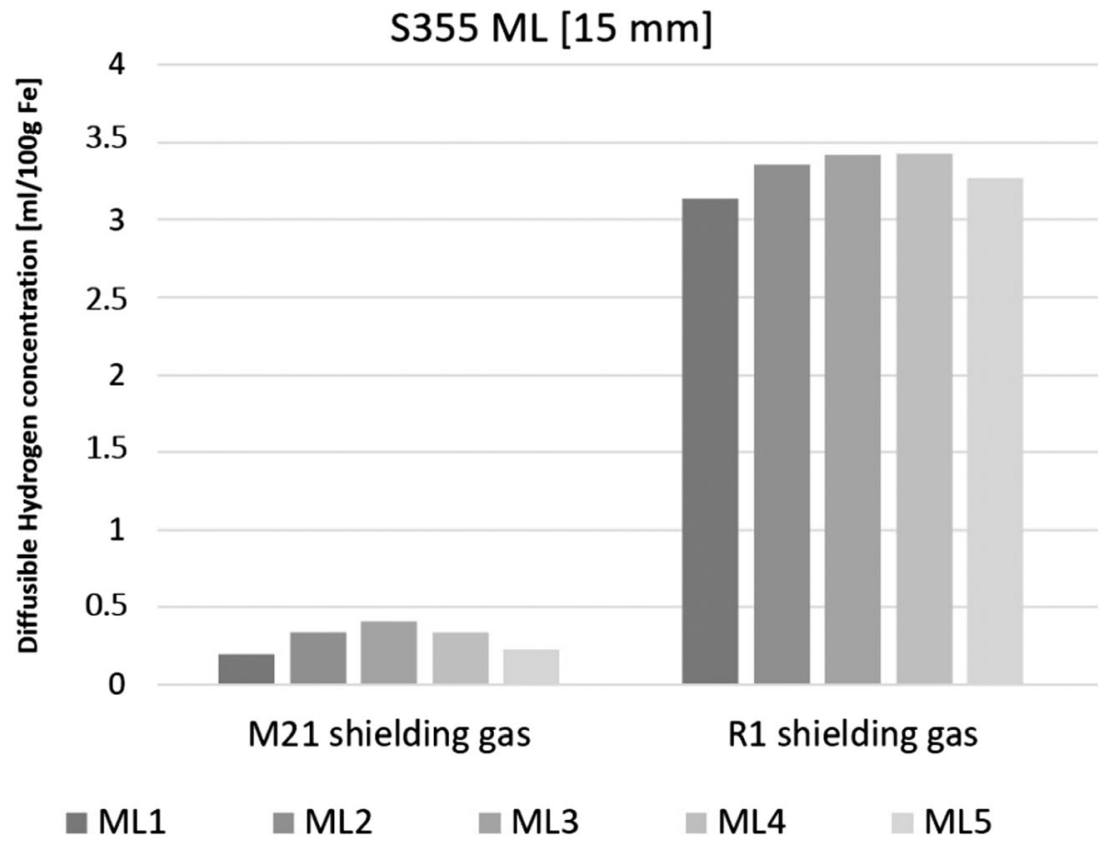


Fig. 7 Diffusible hydrogen concentration in the S460 multipass weld

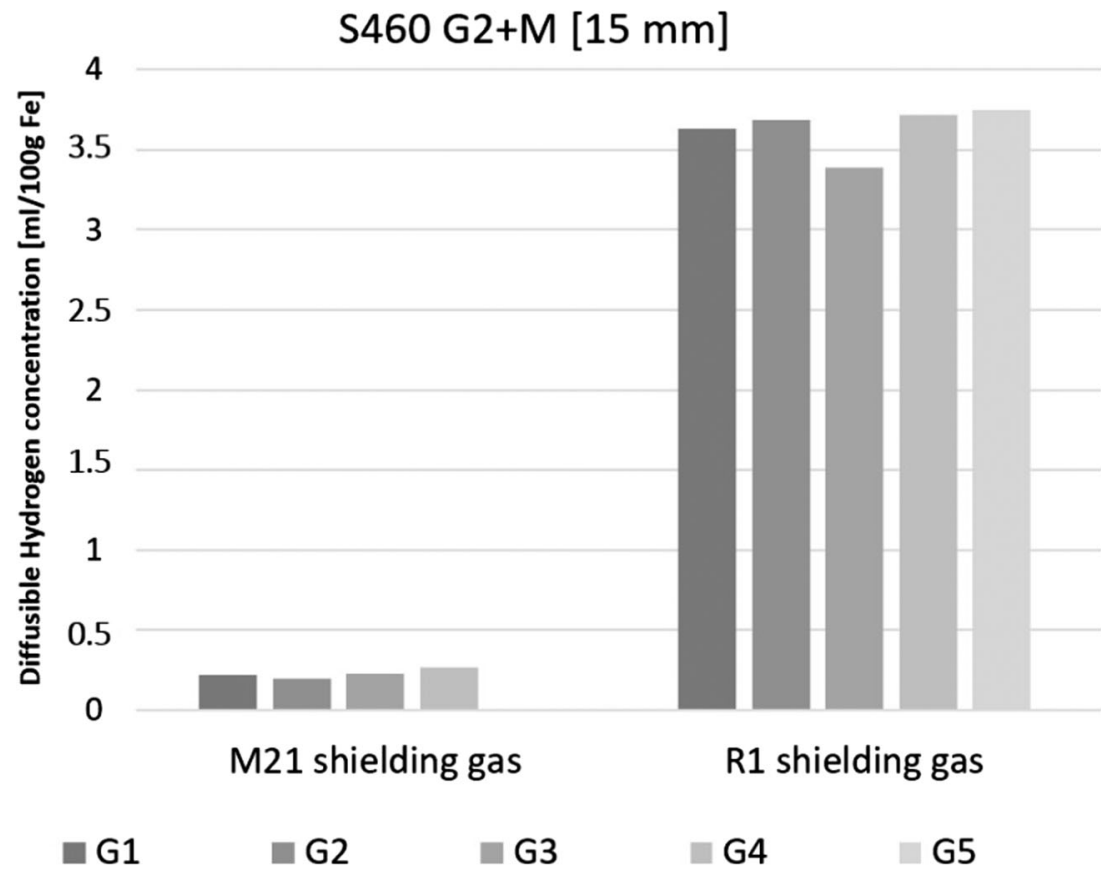

hydrogen concentration in the as delivered condition, but the difference is negligible.

By comparing the multi-pass welding experiments to the ISO 3690 samples (see Section 3.1), the hydrogen concentration is less high due to the longer process duration (by means of repeating thermal cycles). Hydrogen diffusion during multi-pass welding affects the hydrogen concentration [29, $30,33]$. This can be seen by the decreasing measured hydrogen concentration of approximately $3.5 \mathrm{ml} / 100 \mathrm{~g} \mathrm{Fe}$ in the multi-pass welds (see Figs. 6 and 7) compared to $12 \mathrm{ml} / 100$ $\mathrm{g}$ Fe for the ISO 3690 specimens (see Fig. 5), which corresponds to a percentage drop of $75 \%$. Welds with low HD show the same trend. Solid wire and welding with M21 shielding gas show a drop of $67 \%$. Thus, the effect of the prolonged welding time due to the manifold thermal cycles was confirmed.

\subsection{Acoustic emission (AE) analysis}

The AE analysis was performed after welding for at least $48 \mathrm{~h}$ (following [6]). By using free shrinking and modified Tekken test samples in $15 \mathrm{~mm}$ and $40 \mathrm{~mm}$ thickness, the effect of different restraint intensities, i.e., different hindered shrinkage during cooling of the welded sample, was investigated (sample geometry, see Fig. 2). The time of occurrence of crack relevant AE signals depends on the restraint intensity, preheat, and interpass temperature as well as hydrogen concentration and heat input (in case of the $\mathrm{S} 460 \mathrm{G} 2+\mathrm{M}$ ). The results are shown in Fig. 8 for the S355 ML.

Figure 8 shows the time of occurrence of first crack specific AE signals after welding was completed. These crack events must however be validated by NDT and metallographic analysis (including scanning electron microscopy (SEM)) before a statement on the MWT can be done, as shown in Section 3.4.

The experiments no. 1 to 4 shown in Fig. 8 are welding experiments with no additional hydrogen (shielding gas M21), the experiments no. 5 to 8 had been carried out with the addition of hydrogen in the shielding gas (R1 shielding gas). Focusing on the reference points (RP1 and RP2), the point RP2 (with additional hydrogen) shows first events that are related to crack formation, a few minutes earlier than RP1

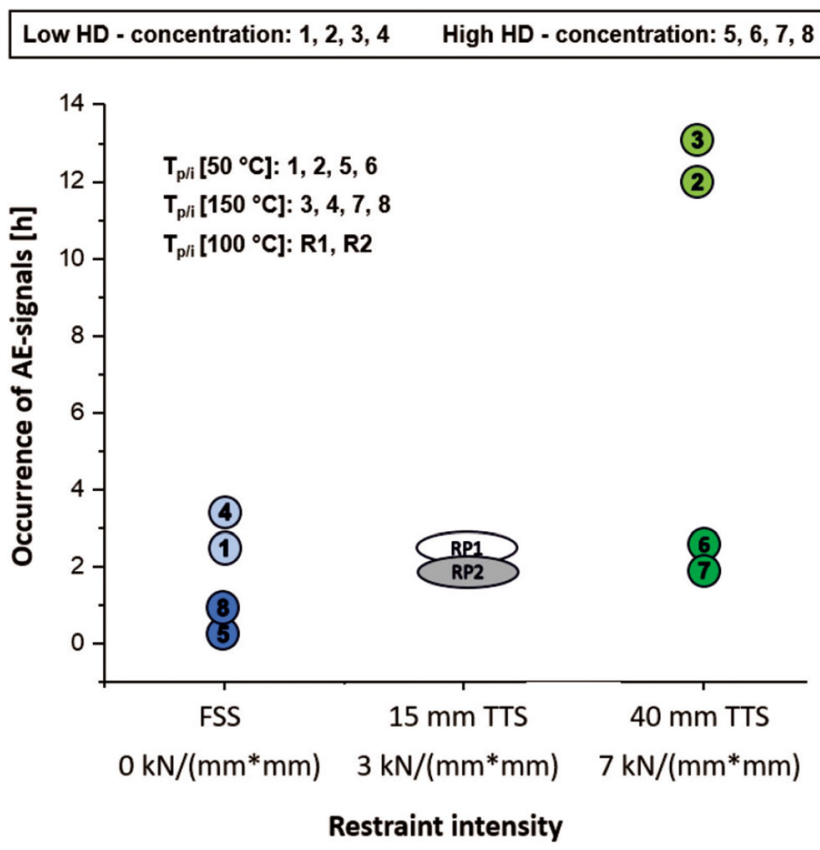

Fig. 8 Occurrence of AE signals based on restraint intensity $[\mathrm{kN} /(\mathrm{mm} \times$ $\mathrm{mm})]$ and $T_{\mathrm{p} / \mathrm{i}}\left[{ }^{\circ} \mathrm{C}\right]$ 
(without additional hydrogen). As expected, experiments with higher hydrogen concentration (points 5 to 8) show AE signals earlier compared to low hydrogen concentration (points 1 to 4$)$, see Fig. 8 .

For the 40-mm modTTS samples, the effect of higher hydrogen concentrations on faster detection of crack relevant signals is more pronounced. The timeframe between the experiments with shielding gas R1 (points, 6 and 7) and shielding gas M21 is more than $8 \mathrm{~h}$. The influence of the preheat/interpass temperature on the occurrence of crack relevant signals is negligible, but higher preheat/ interpass temperature shows a slight trend to delay the occurrence of crack signals. Increasing preheat/interpass temperature leads to longer cooling times and thus results in extended time for hydrogen effusion, consequently lower hydrogen concentration after welding, and lower risk of brittle microstructures which are prone for HACC. Nevertheless, the influence of higher temperature and long cooling periods (i.e., high heat input and interpass temperature) on hydrogen concentration was shown in [26]. The amount of hydrogen that is introduced during welding cannot be sufficiently reduced by the applied welding sequence or controlled preheat and interpass temperatures (i.e., cooling time) as compared to a so-called hydrogen removal heat treatment after welding [29, 30, 33].

Comparing the FSS to the modTTS regarding the restraint intensity shows contradictory results with respect to expectations. FSS (points, 1, 4, 5 and 8) show AE signals earlier than modTTS. The fact that FSS with low restraint intensities $\left(R_{\mathrm{Fy}}\right.$ $-0 \mathrm{kN} /(\mathrm{mm} \times \mathrm{mm}))$ show crack relevant AE signals and they appear also for low-HD experiments. These results show increasingly that NDT and metallographic analysis is important for a validation of the $\mathrm{AE}$ results and to give a statement on the MWT.

Based on the results shown in Table 4, the S460 G2+M (points, A-D) was compared with the S355 ML (point, R1 and R2 - both 15-mm modTTS). The preheat/interpass temperature was set to $100{ }^{\circ} \mathrm{C}$ and the heat input $\mathrm{E}$ was varied from 0.8 to $1.6 \mathrm{~kJ} / \mathrm{mm}$. A comparison of both materials is possible by the fact that the measured diffusible hydrogen concentration $(\mathrm{ml} / 100 \mathrm{~g} \mathrm{Fe})$ for the materials was the same (discussed in Section 3.2). Additionally, the restraint intensities are the same for both base materials. The AE signals for the S460 appear in the same time interval as the reference points of the S355 (points, RP1 and RP2; see Fig. 8). Comparing the S460 to the S355 with a detailed look on the measured time for AE signals, the S460 showed overall slightly faster AE signals (approximately, 30-40 min.). This is due to the higher yield strength resulting in a higher risk for HACC in the S460 G2+M. Nevertheless, the effect of the higher yield strength is not remarkable and time for occurrence of crack relevant signals can be regarded as similar for both materials, as well as the effect of heat input that is negligible with respect to the occurrence of crack relevant signals.

\subsection{NDT and metallographic analysis of the weld joints}

After AE analysis was done, excessive non-destructive testing (NDT) was performed for all welding experiments, to validate the measured $\mathrm{AE}$ events whether cracks appeared or other defects that can perhaps be related to the AE events (release of thermomechanical stresses by global deformation). Visual testing (VT), magnetic article testing (MT), and X-ray testing (RT) as well as ultrasonic testing (UT) was done. No relevant defects regarding cracks were detected by VT and MT. Relevant indications were detected using RT and UT especially for welding experiments with high HD concentration (experiments with shielding gas R1). The main findings from NDT are summarized in Table 5. For that reason, the " $X$ " marks relevant indications that were found with RT and UT technique

The welding experiments having a high HD and higherrestraint intensities were investigated first, as these experiments were expected to have the highest risk for HACC. Based on the findings from these investigations, not all the other welding experiments were further investigated by UT. Additionally, relevant indications need to be discussed with respect to the geometry of the welding specimens and location of detected indications by UT (see Fig. 1c). Small gaps in the beginning and end remained by using GMAW to build up the weld joint (see Fig. 9). In these regions, welding defects appeared that were found by UT. By keeping the restraint intensity low (FSS) and with high-HD level, some failures were

Table 5 Relevant indications detected by RT and UT

\begin{tabular}{|c|c|c|c|c|}
\hline Test point & Restraint intensity & HD level & RT & UT \\
\hline R1 & Medium & Low & - & - \\
\hline $\mathrm{R} 2$ & Medium & High & $\mathrm{X}$ & $\mathrm{X}$ \\
\hline 1 & Low & Low & - & n.t. \\
\hline 2 & High & Low & - & $\mathrm{X}$ \\
\hline 3 & High & Low & - & $\mathrm{X}$ \\
\hline 4 & Low & Low & - & n.t. \\
\hline 5 & Low & High & $X$ & n.t. \\
\hline 6 & High & High & $\mathrm{X}$ & $\mathrm{X}$ \\
\hline 7 & High & High & $\mathrm{X}$ & $\mathrm{X}$ \\
\hline 8 & High & High & $X$ & n.t. \\
\hline 460_A & Medium & Low & - & - \\
\hline 460_B & Medium & High & $X$ & $X$ \\
\hline 460_C & Medium & Low & - & - \\
\hline 460_D & Medium & High & $\mathrm{X}$ & $\mathrm{X}$ \\
\hline
\end{tabular}

$X$ relevant failure indications, $n$.t. not tested 


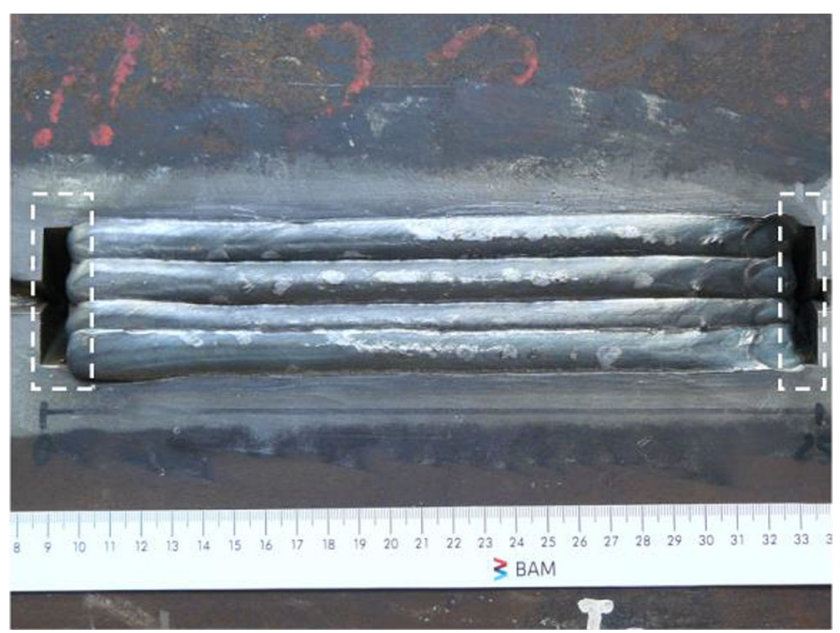

Fig. 9 Welded 40-mm modTTS with gaps in the start and end of the weld seam

found with RT, but these were in general small pores. Critical conditions for HACC were reached by test point 6 and 7 (see Table 5). On the one hand, side NDT (first of all UT) was useful to find failure indications in general, but on the other side a further metallographic analysis was necessary to identify the failure indications and to validate weather the indications are cracks (cold cracks or hot cracks) or other defects in the weld seam.

After NDT was done, smaller specimens were extracted from the welded samples by saw cutting for metallographic examination. Eight to ten metallographic specimens were prepared for each weld joint according to the findings of NDT (UT and RT) presented in Table 5. Detailed metallographic analysis of the extracted weld seams showed small pores and small micro cracks, like those seen in Fig. 10, mainly in the start and end of the weld seam. However, none of these micro cracks of or pores showed further crack propagation or formation of macroscopic cracks, even at higher hydrogen concentrations.

Two markable indications found by NDT (RT and/or UT), but only in the end of the weld seam, could be confirmed as cracks by metallographic analysis, see Fig. 11 (S355 ML in 40 $\mathrm{mm}$ ). Only for high-restraint intensities in combination with high-HD (welding with shielding gas R1) defects like those seen in Fig. 11 were found showing typical fracture surfaces analyzed by SEM (Phenom XL) after opening them carefully.

Both cracks (see Fig. 11a, b) were investigated by SEM and the fracture surface of the cracks is presented in Figs. 12 and 13. The fracture morphology in Fig. 12 shows typical features of a hot crack, see in the lower part of the picture. The dendrites have a regularly structure. In the upper part of the picture, a trans-granular cleavage fracture surface is seen which perhaps results from HACC originating from the formally formed hot crack in the end crater of the first pass. The hot crack acts as notch-inducing high stresses and strains at its crack tips acting as initiation sites for further HACC propagation at higher hydrogen concentrations. The hot crack possibly formed due to the high-restraint intensity of the modTTS sample [32]. The geometry of the modTTS samples does not allow for putting the weld start and end to run-on and run-off plates and directly influence the test results. Thus, these parts need to be analyzed carefully with respect to statements on cracking, as the start and end of a weld is normally put to a run-on or run-off plate or specially treated to avoid occurrence of weld defects, which predominantly occurs in the beginning or end of a weld. Nonetheless, it is seen in Fig. 11a and $b$ that in both cases there are small cracks propagating from the upper and lower tip of the hot crack, despite of preheat and interpass temperature. In the case of the higher working temperature, the hot crack as well as the HACC originating from the hot crack is much smaller compared to the lower working temperature. The shorter HACC possibly is due to the lower resulting hydrogen concentration in the weld seem with increasing working temperature.

The upper part of Fig. 13 also shows a brittle surface of a trans-granular cleavage fracture. In the lower part of Fig. 13, a smooth surface with dendrites having a regular shape is clearly seen, which is identified as a hot crack [31,32]. Thus, in both cases, hot cracks formed in the end crater of the first pass due to high-restraint weldability test (modTTS) [32] which act as notch-inducing high stresses and strains. Thus, these hot cracks initiate HACC during cooling due to locally increased stresses and strains around the hot cracks and hydrogen diffusion towards these areas. Nevertheless, the hot cracks would have been detected by NDT directly after welding and cooling down to ambient and must be removed from the weld.

By NDT testing, the AE signals were identified over the entire weld seam and validated by NDT and metallographic analysis. Welding defects and failure indications were found mainly at the start and end of the weld seam. With respect to the crack relevant AE signals compared to the results of NDT,

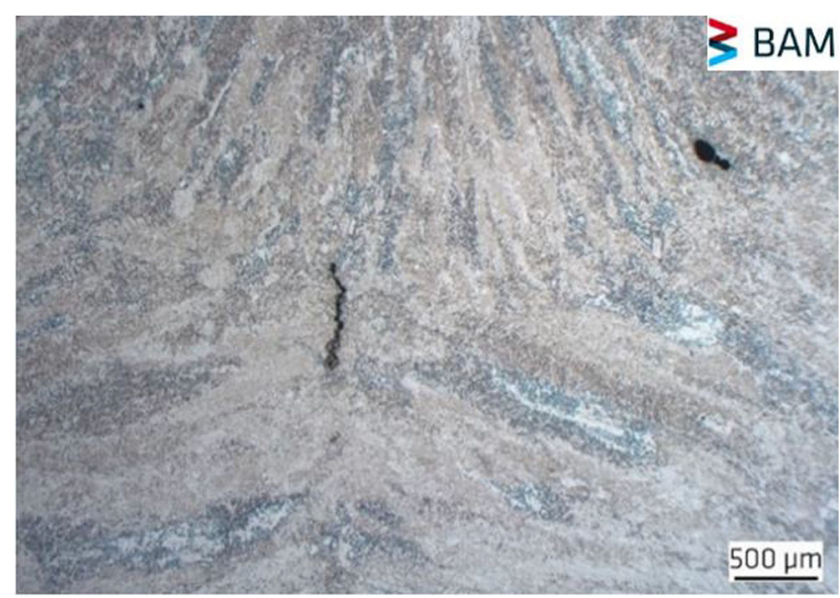

Fig. 10 Weld defects found with metallographic analysis of the 40-mm modTTS with high HD 
Fig. 11 Defects in the end of the weld seam: a $40-\mathrm{mm}$ modTTS sample with $T_{\mathrm{p} / \mathrm{i}}: 150{ }^{\circ} \mathrm{C}$ and high HD and b 40-mm modTTS sample with $T_{\mathrm{p} / \mathrm{i}}: 50^{\circ} \mathrm{C}$ and high $\mathrm{HD}$
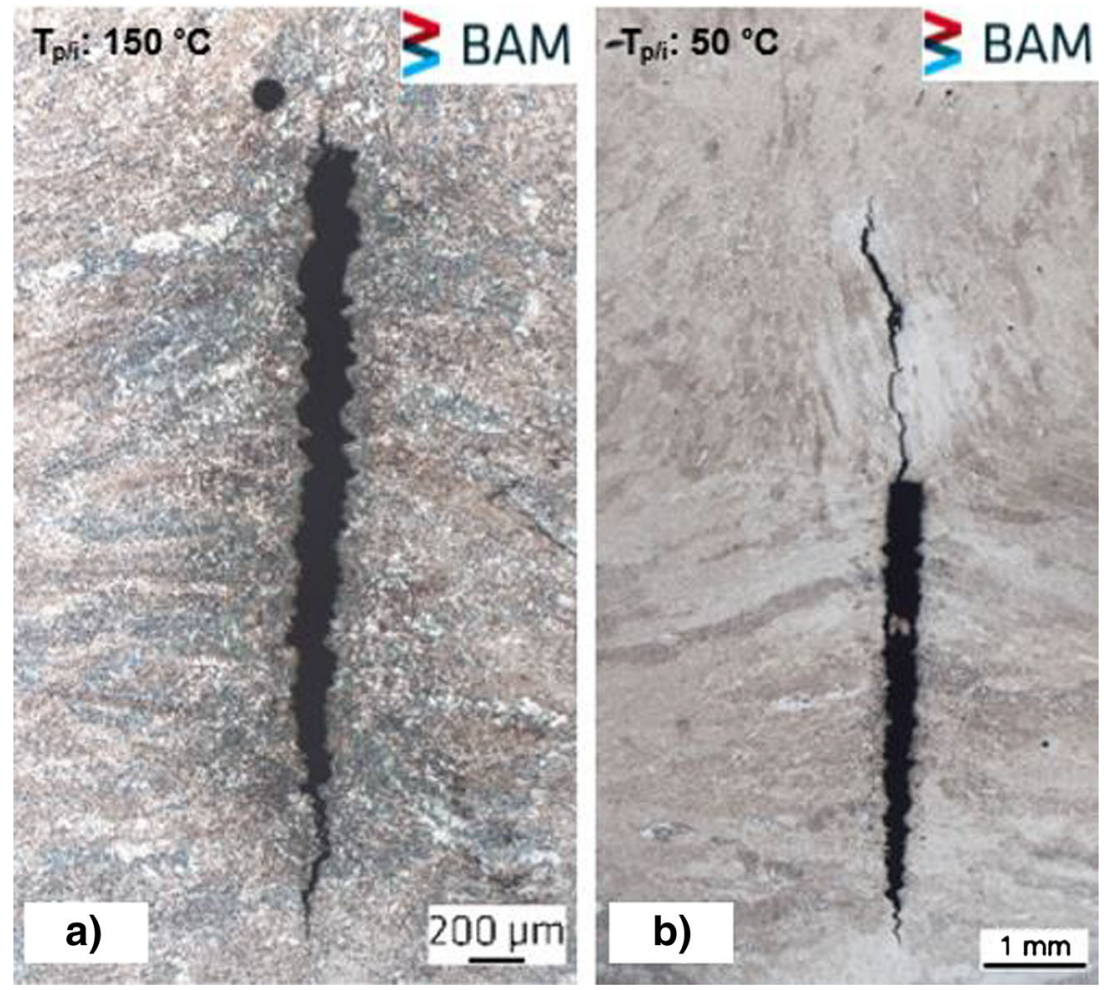

metallographic analysis, and SEM, no remarkable HACC were found in the middle part of the weld seam. The microcracks and defects that are shown in Figs. 10 and 11 show characteristics of hot cracks like smooth surface and clear oriented packages of dendrites with a round shape, in accordance with [32] (see Figs. 12 and 13). Furthermore, the

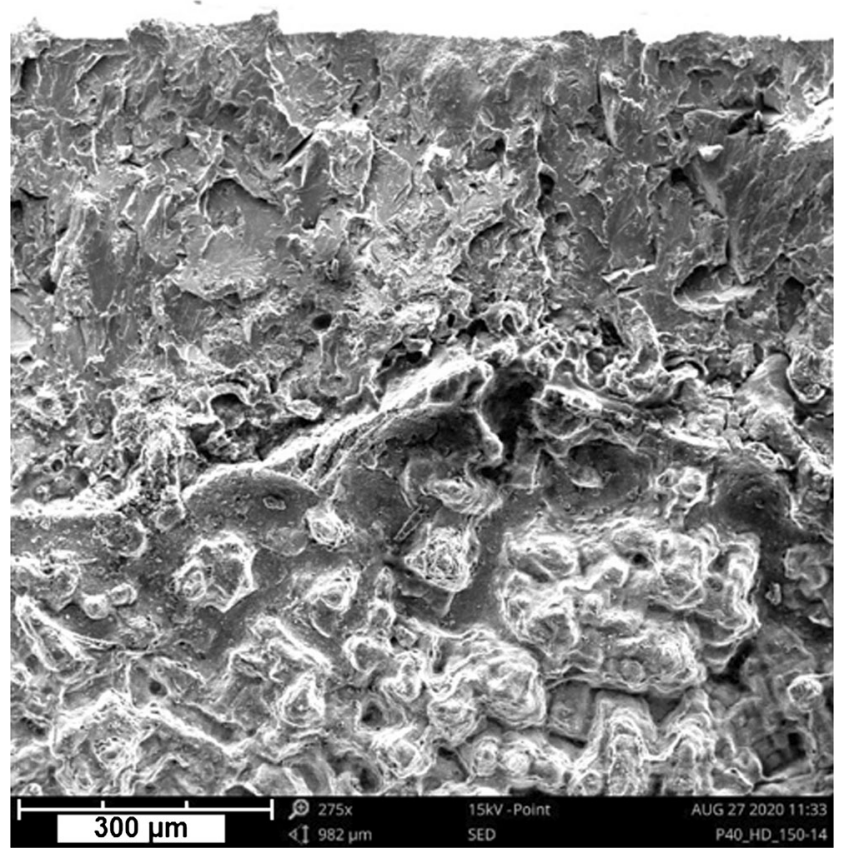

Fig. 12 Fracture surface of a 40-mm modTTS (welded with shielding gas R1) upper part of Figs. 12 and 13 shows brittle fracture surfaces having a characteristic fracture morphology of a HACC. The hot cracks occurred during welding in the end crater of the weld and initiated HACC during cooling. But these cracks did not propagate through the whole weld seam reaching any

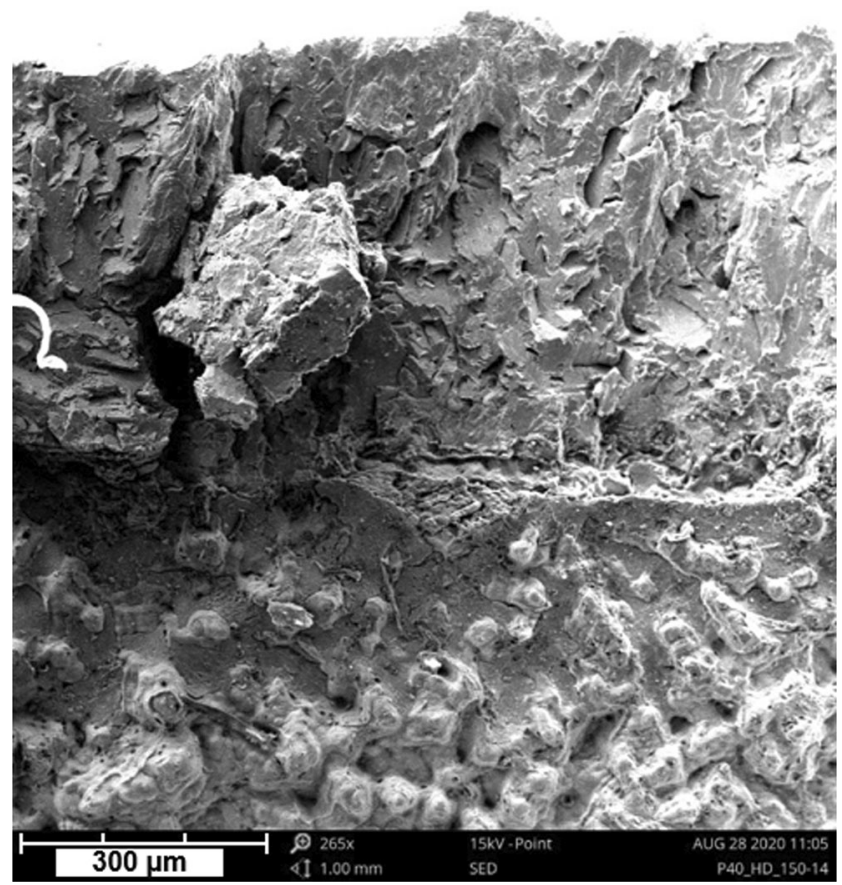

Fig. 13 Fracture surface of a 40-mm modTTS with brittle and ductile surface (welded with shielding gas R1) 
surface. Nonetheless, the hot cracks would have been detected by NDT directly after welding and thus also an emanated cold crack would have been detected.

At least it is not clear if the cold cracks, emanated from the hot cracks, occurred directly after welding and cooling to ambient or delayed after 2 to $3 \mathrm{~h}$ as indicated by AE signals of points 6 and 7. However, these cold cracks have been triggered by hot cracks and possibly would not have been occurred in a hot crack free weld. Thus, these both HACC are the only "delayed" cracks found in the tested specimens within a waiting time of $48 \mathrm{~h}$ before NDT.

In large welding components, HACC typically occurs transverse to welding direction, but this type of HACC cannot be considered using the small modTTS specimens. Nonetheless, larger test samples allowing for longer welds and high longitudinal restraint intensities and thus representing a higher risk for transverse HACC must be carried out in the future and further statements as well as transferability of the results to real welded OWT components.

\section{Conclusions and outlook}

In the present study, weld joints made of structural steel S355 ML were investigated and compared to the offshore steel grade $\mathrm{S} 460 \mathrm{G} 2+\mathrm{M}$, aiming to create a scientific basis for a reduction of MWT before NDT. Weld joints with a thickness of $15 \mathrm{~mm}$ and $40 \mathrm{~mm}$ were examined. The samples were joined by GMAW using a shielding gas with addition of hydrogen and the time until cracks appear which was detected via $\mathrm{AE}$ for at least $48 \mathrm{~h}$ after welding. To consider a corresponding restraint intensity of a real weld joint in an OWT a modified Tekken test geometry (modTTS - cold cracking test) was used. Depending on weld heat input, restraint intensity, preheat/interpass temperature, and hydrogen content following conclusions can be drawn with respect to delayed cracking:

- All measured AE signals appear in a time range of $4 \mathrm{~h}$ after welding was done. AE signals based on welding experiments with the shielding gas R1 (high hydrogen concentration) appear slightly faster for both steels, the S355 ML as well as for the S460 G2+M.

- Cracks and other failure indications were determined in the weld joint by NDT and compared to AE to validate the detected signals. UT and RT do not fully support the results achieved with AE, by means of not all detected signals in AE analysis could be confirmed by NDT or metallographic analysis. Some of the signals detected by AE are possibly thermal relaxations during cooling of the sample.

- Welding defects mainly occurred in the start and end of the welds. As these parts of the welds could not be excluded from the test welds in the modTTS specimens, the results have to be analyzed carefully and validated by NDT.

- SEM proved the cracks found by NDT and metallographic examination to be hot cracks. These hot cracks acted as initiation sites for HACC, seen by a brittle trans-granular fracture surface emanating from the hot crack. As these HACC were triggered by hot cracks in the end crater of the first pass, they possibly would not have occurred in a hot crack free weld.

- All relevant AE signals appeared within a timeframe of maximum $14 \mathrm{~h}$ after welding. That means the MWT in the standards is perhaps too conservative. Nonetheless, further investigations are necessary to validate the experimental results from this study. This encompasses the establishment between the restraint condition of large-scale OWT components and the modified Tekken test geometry. This can be supported by FEM analyses.

- The small-scale tests used in this study is suitable for a fast screening of different welding conditions, but its effectivity is currently limited to map real OWT welding conditions. Thus, larger test samples must be investigated having a longer weld seam length to also allow for transverse HACC cracking in the weld seam and HAZ. Hence, further investigations are needed for sustainable statements on a reduction of MWT in this type of steels.

Acknowledgments The investigations in this study were funded by the German Steel Research Association FOSTA e.V., grant no. P 1259/32/ 2017 / S 024/ 10243/17. Sincere thanks are given to the companies and project partners which were actively involved in the project. The author also wants to thank Mr. Götsch (Div. 9.2, BAM, Berlin) for the water jet cutting as well as Mr. Heckel (Div. 8.4, BAM) for the NDT experiments and Mrs. Marten and Mrs. Kirstein (Div. 9.3, BAM) for the metallographic analysis.

Funding Open Access funding enabled and organized by Projekt DEAL.

Open Access This article is licensed under a Creative Commons Attribution 4.0 International License, which permits use, sharing, adaptation, distribution and reproduction in any medium or format, as long as you give appropriate credit to the original author(s) and the source, provide a link to the Creative Commons licence, and indicate if changes were made. The images or other third party material in this article are included in the article's Creative Commons licence, unless indicated otherwise in a credit line to the material. If material is not included in the article's Creative Commons licence and your intended use is not permitted by statutory regulation or exceeds the permitted use, you will need to obtain permission directly from the copyright holder. To view a copy of this licence, visit http://creativecommons.org/licenses/by/4.0/.

\section{References}

1. Rohrig K, Richts C, Bofinger S (2016) Energiewirtschaftliche Bedeutung der Offshore-Windenergie für die Energiewende. Iwes.fraunhofer.de. https:/www.fraunhofer.de/content/dam/zv/dd/ 
forschungsthemen/energie/EnergiewirtschEnergiew-Bedeutungvon-Offshore-Windenergie.pdf. Accessed 12 July 2020

2. Climate protection program of the German Federal Government (2030) https://www.bundesregierung.de/breg-de/themen/ klimaschutz/klimaschutzprogramm-2030-1673578. Accessed 10 July 2020. Accessed 05 July 2020

3. Windenergy - Report for Germany (2018) Fraunhofer-Institut für Energiewirtschaft und Energiesystemtechnik (IEE). http:// windmonitor.iee.fraunhofer.de/opencms/export/sites/windmonitor/ img/Windmonitor-2018/WERD_2018_barrierefrei.pdf. Accessed 12 July 2020

4. Martin F, Schröter F (2005) Stahllösungen für OffshoreWindkraftanlagen, vol 74. Ernst\&Sohn, pp 435-442. https://doi. org/10.1002/stab.200590089

5. Hanus F, Schütz J, Schütz W. (2002) One step further. OMAE2002-28193. pp 167-172. doi:https://doi.org/10.1115/ OMAE2002-28193

6. EN 1090-2 (2018) Execution of steel structures and aluminium structures - Part 2. Technical requirements for steel structures

7. DNVGL-OS-C401 (2015) Fabrication and testing of offshore structures. DNV GL AS July 2015

8. Nevasmaa P (2003) Predictive model for the prevention of weld metal hydrogen cracking in high-strength multipass welds. Dissertation. University of Oulu. p 254, ISBN: 951-42-7181-5

9. EN 10225-1 (2009) Weldable structural steels for fixed offshore structures. Technical delivery conditions - Part 1: Plates

10. Hanus F (2000) Thermomechanisch gewalzte Stähle für den Stahlund Behälterbau. Presentation „Schweißen der thermomechanisch gewalzten Feinkornbaustähle“. SLV-Duisburg. p 10

11. EN ISO 3690 (2012) Welding and allied processes. Determination of hydrogen content in arc weld metal

12. Martin F, Schröter F (2006) Neuste Entwicklungen von thermomechanisch gewalzten Feinkornbaustählen - Erfahrungen aus Offshore-Industrie und Stahlwasserbau. Stahlbau 75(11):875881. https://doi.org/10.1002/stab.200610097

13. Neuhaus M (2005) Zum Einfluss der Schrumpfbehinderung auf das thermomechanische Verhalten geschweißter Bauteile. Shaker Verlag, Aachen 3-8322-4126-4

14. Pargeter R (2003) Evaluation of necessary delay before inspection for hydrogen cracks - postweld crack development was monitored over time on a variety of test welds. Weld J 82(11):321-329

15. EN ISO 14341 (2011) Welding consumables - wire electrodes and weld deposits for gas shielded metal arc welding of non-alloy and fine grain steels

16. EN ISO 17632 (2015) Welding consumables. tubular cored electrodes for gas shielded and non-gas shielded metal arc welding of non-alloy and fine grain steels

17. EN ISO 17642 (2015) Destructive tests on welds in metallic materials -cold cracking tests for weldments - Arc welding processes

18. Kannengiesser T, Böllinghaus T (2013) Cold cracking tests - an overview of present technologies and applications. Weld World 57(1):3-37. https://doi.org/10.1007/s40194-012-0001-7

19. EN ISO 14175 (2008) Welding consumables - gases and gas mixtures for fusion welding and allied processes
20. Rhode M (2016) Hydrogen diffusion and effect on degradation in welded microstructures of creep-resistant low-alloyed steels. Dissertation, Otto-von-Guericke-Univ, BAM-Dissertationsreihe, Band 148. ISBN: 978-3-9817853-3-3

21. Rhode M, Schaupp T, Münster C, Mente T, Böllinghaus T, Kannengiesser T (2019) Hydrogen determination in welded specimens by carrier gas hot extraction - a review on the main parameters and their effects on hydrogen measurement. Weld World 63(2): 511-526. https://doi.org/10.1007/s40194-018-0664-9

22. Salmi S, Rhode M, Jüttner S, Zinke M (2015) Hydrogen determination in 22MnB5 steel grade by use of carrier gas hot extraction technique. Weld World 59:137-144. https://doi.org/10.1007/ s40194-014-0186-Z

23. Shiraiwa T, Kawate M, Briffod F, Kasuya T, Enoki M (2020) Evaluation of hydrogen-induced cracking in high-strength steel welded joints by acoustic emission technique. Mater Des 190: 108573. https://doi.org/10.1016/j.matdes.2020.108573

24. Tillmann W, Walther F, Luo W (2018) In situ acoustic monitoring of thermal spray process using high-frequency impulse measurements. J Therm Spray Technol 27:50-58. https://doi.org/10.1007/ s11666-017-0673-z

25. EN 100205-4 (2011) Hot rolled products of structural steels - Part 4. Technical delivery conditions for thermomechanical rolled weldable fine grain structural steels

26. Wongpanya P (2008) Effects of heat treatment procedures on the cold cracking behaviour of high strength steel welds. Dissertation, Helmut Schmidt University Hamburg, BAM-Dissertationsreihe, Band 36. ISBN: 978-3-9812072-7-9

27. Schaupp T, Rhode M, Kannengießer T (2019) Influence of welding parameters on diffusible hydrogen content in high-strength steel welds using modified spray arc process. Weld World 62:9-18. https://doi.org/10.1007/s40194-017-0535-9

28. Padhy GK, Komizo Y (2013) Diffusible hydrogen in steel weldments - a status review. Trans JWRI 42(1):39-62

29. Mente T, Böllinghaus T, Schmitz-Niederau M (2013) Heat treatment effects on the reduction of hydrogen in multi-layer highstrength weld joints. Weld World 56:26-36. https://doi.org/10. 1007/BF03321362

30. Steppan E, Mente T, Böllinghaus T (2013) Numerical investigations on cold cracking avoidance in fillet welds of high-strength steels. Weld World 57:359-371. https://doi.org/10.1007/s40194013-0036-4

31. Lee M, Cho K, Kim Y, Kang N (2015) Effect of martensite on cold cracking in 600-MPa grade flux-cored arc weld metals using the $\mathrm{Y}$ groove test. Weld World 59:647-654. https://doi.org/10.1007/ s40194-015-0240-5

32. Lippold JC (2015) Welding metallurgy and weldability. John Wiley \& Sons Inc., Hoboken

33. Bailey $\mathrm{N}$ et al (1993) Welding steels without hydrogen cracking, 2nd edn. Woodhead Publishing Limited, Cambridge

Publisher's note Springer Nature remains neutral with regard to jurisdictional claims in published maps and institutional affiliations. 